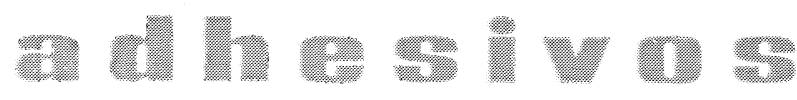

J. G. KENNEDY

Building Materials, n. ${ }^{\circ}$, agosto 1967, pág. 31

El costo de los adhesivos por $\mathrm{m}^{2}$ es despreciable si se compara con el costo del propio solado; pero, si se tiene en cuenta que el adresivo debe durar más que el pavimento, es evidente que el aspecto económico no interviene en el problema de su elección. El problema consiste en elegir el adhesivo más adecuado para cumplir las condiciones pertinentes en el momento de realizar el pavimento. Estas comprenderán el tipo de solado y base, y su calidad, lo cual dará una idea de lo que tiene que durar el adhesivo, el tipo de desgaste que cabe esperar que resista el pavimento, la temperatura y la humedad.

Otro aspecto muy importante es el de un tiempo de fraguado aceptable, ya que no siempre es cierto el afirmar que los adhesivos con un tiempo de fraguado prolongado proporcionan mayor adherencia. Algunos secan tan rápidamente que el pavimento debe colocarse al cabo de muy pocos minutos de haberse aplicado el pegamento.

Con la aparición de tantos adhesivos sintéticos, la facultad de elección se encuentra entre cola, pasta o disoluciones de caucho, y hay una variedad abrumadora donde elegir. Es de esperar que con esta recapitulación la elección resulte menos confusa. En la tabla se muestran los distintos pavimentos y algunos de los adhesivos que se recomiendan para cada uno de ellos.

Si se siguen -en lo posible- las instrucciones del fabricante sobre el tipo de adhesivo que debe emplearse, y se respetan al pie de la letra las instrucciones de instalación, la obra terminada será la más durable. Sin embargo, en muchos casos las condiciones puede que no ajusten exactamente a las especificadas por los fabricantes de suelos, que no haya posibilidad de conseguir los adhesivos recomendados, o que los tiempos de secado no sean adecuados para un trabajo realizado a mano.

\section{BALDOSAS CERAMICAS}

Un adhesivo muy rápido para fijar baldosas cerámicas es el "Romanite 248" (de la Andrew Maxwell Division of Liverpool Borax Co.): Primeramente el piso debe de estar completamente seco, libre de polvo y nivelado (si es de hormigón, se humedecerá en la forma normal). El adhesivo no diluido se esparcerá abundantemente por la parte posterior y los cantos de las losetas y seguidamente se sentarán. Dichas losetas estarán en condiciones de pisarse al cabo de 1 hora de haberlas fijado. Este adhesivo no es adecuado cuando hay humedad ascendente. 
CORCHO

LINOLEO Y CORCHO MOQUETAS

CAUCHO

LOSETAS (cerámicas)

C.P.V. (forradas)

C.P.V. ( $\sin$ forrar)

C.P.V. (losetas de amianto vinilo)

LOSETAS TERMOPLASTICAS DE SOLAR

BLOQUES DE MADERA
Cola al agua a base de lignina.

Prácticamente todos los adhesivos para suelos, es decir, de fraguado quimico, disolventes, emulsiones o mezclas con agua.

Cementos de caucho-látex (de fraguado químico) o disolventes naturales o sintéticos a base de soluciones de caucho.

Cemento de emulsiones de A.P.V.

Adhesivos a base de almidón, caseina o lignina (disueltos en agua), adhesivos a base de emulsiones de betún o látex, adhesivos de goma en disolventes volátiles o cementos de caucho-látex.

Emulsiones de látex sintético o natural.

Emulsiones de caucho/betún, emulsiones de látex natural o sintético, adhesivos de cut-back con betún (disolvente).

Emulsiones de caucho/betún, betún emulsionado, emulsiones de betún cut-kack de betún.

Emulsiones de betún. Emulsiones de A.P.V.

recomendados por los fabricantes de pavimentos.

Cuando existen humedades es aconsejable aplicar primero una capa de Semi-mastic "E", de la ya citada Liverpool Borax Co.: Este producto es una combinación de betún y fibras de amianto que, sobre una capa de hormigón de áridos finos, forma una capa impermeabilizante resistente al vapor. Si la capa de hormigón es áspera, se tratará primero con una imprimación bituminosa. El Semi-mastic "E" también sirve como adhesivo y puede utilizarse para fịar una membrana de papel metálico, de fibra de vidrio o de fieltro de techar.

Otra posibilidad para los baldosines cerámicos es la de emplear una emulsión de A.P.V. tal como Polystic de la Croid. Ltd.: Es una emulsión de acetato de polivinilo plastificada que forma una fuerte película adhesiva cuando se seca. Esta película no se afecta por la humedad, ni petróleo, aceites, grasas, hongos, ácidos y álcalis débiles, pero puede reblandecerse con alcohol metílico. Si se utiliza sobre madera puede reblandecerse después de prolongado contacto con el agua. No se llega a vølver quebradiza ni se deteriora al envejecer.

Un adhesivo a base de una emulsión acuosa de secado rápido es el conocido como Hi Bond (de la Allied Building Commodities): Secará aproximadamente en 2 horas. Puede aplicarse a superficies lisas y sólidas y es impermeabilizante, resistente a los aceites, petróleo, grasas, mantillo, hongos, ácidos y álcalis débiles. 


\section{BLOQUES DE MADERA}

Cada vez se utiliza más el procedimiento de emplear adhesivos en frío en pavimentos de bloques de madera, en oposición a los primitivos métodos de utilizar alquitrán caliente: Un compuesto de betún y caucho que no requiere calentamiento y que proporciona una tenaz adherencia es el Colset, adhesivo para bloques de madera de la Bitumen Industries $L t d$. No es recomendable su utilización sobre maestreados húmedos o sobre maestreados en los cuales se ha incorporado un agente impermeabilizante. Las bases húmedas o pulverulentas se dotarán de una imprimación. El procedimiento es muy sencillo: las caras inferiores de los bloques se bañan simplemente con el adhesivo sin diluir, dejándolas secar durante 24 horas.

También pueden emplearse emulsiones de A.P.V. (como las que suministra la Croid Ltd.): Son de utilización más limpia, pero no se recomienda su uso cuando se precise un cierto grado de resistencia al agua. Este material puede utilizarse además como un revestimiento con tableros de virutas.

La compañía también sugiere el cemento de caseína como un posible adhesivo para los pavimentos de bloques de madera: Este producto es extremadamente durable y no inflamable, pero tiene el inconveniente de que mancha la madera y puede producir inflamaciones si se pone en contacto con la piel.

El Hi-Bond, descrito antes, se recomienda generalmente para pavimentos de bloques.

Otro producto, especialmente recomendado para bloques de madera y suelos de parquet, es una emulsión de A.P.V. de la Bostik Ltd.: No le afecta ni la helada ni el calor hasta $70^{\circ} \mathrm{C}$. Se aplica fácilmente con brocha y su resistencia al agua, aceite y agentes químicos es buena. Para pavimentos de parquet se diluye en 20 partes de agua, secando esto rápidamente.

\section{CORCHO Y LINOLEO}

Bostik fabrica otro adhesivo sintético de látex/resina: Sirve para pegar linóleo, corcho (o plástico) a los maestreados de cemento, al hormigón o a la madera. No es inflamable ni tampoco tóxico y su consistencia es tal que puede aplicarse con llana sobre la base del pavimento. Su resisiencia al agua y a los productos químicos es buena, y en servicio resiste temperaturas desde $-15^{\circ}$ hasta $+75^{\circ} \mathrm{C}$.

El adhesivo denominado L 128 lo recomienda la Armstrong Cork Co. Ltd.: Se utiliza para pegar corcho, losetas cerámicas, lámina de linóleo y losetas de papel de fieltro y subsuelos. No se recomienda directamente sobre el subsuelo de tierra, o cuando se prevea derramamiento de agua. Cuando se requiera resistencia al agua se recomienda el adhesivo L 520 .

\section{PAVIMENTOS VINILICOS}

Los pavimentos vinílicos contienen una cierta cantidad de plastificantes en su composición, y como es bien sabido, los plastificantes tienen cierta tendencia a emigrar desde el pavimento al adhesivo, haciendo que se ablande éste. En el caso de losetas, el adhesivo tiende a aparecer por entre las rendijas, afeándose su aspecto. 
Las investigaciones han demostrado que los suelos de losetas vinílicas se hacen inservibles al levantarse, abarquillarse, retraerse, etc., más bien que por desgaste o rotura; para combatir esto se ha elaborado un adhesivo especial por la Leicester, Lovell \& Co. Ltd., que es resistente a los plastificantes: Nunca endurece ni se hace quebradizo, sino que retiene un cierto grado de flexibilidad. Tiene un período "abierto" después de su aplicación de 20 minutos, no es tóxico, ni inflamable, y, puesto que resiste temperaturas de hasta $50^{\circ} \mathrm{C}$, es adecuado para su utilización en suelos con calefacción subterránea. La superficie sobre la cual se aplique deberá ser sólida, seca y estará libre de grasa o polvo. En superficies muy porosas se aplicarán dos capas de adhesivo. El suelo puede ser utilizado transcurridas 4 horas después de haber sido colocado el pavimento.

Otro adhesivo que se recomienda para losetas vinílicas es el Evo-Stik S.H. 100: Es un cemento sintético de un solo componente que tiene cualidades similares a las de las mismas losetas, es decir, es impermeable, resiste a las grasas y al petróleo y soporta altas temperaturas y los ácidos diluidos. Se adhiere fuertemente a las superficies no porosas y alcanza sus resistencias ćptimas al cabo de 4 días. Sin embargo, una de las ventajas de este adhesivo es su alta adhesividad inicial, por lo cual el suelo puede utilizarse inmediatamente después de haberse colocado. Por esto es eminentemente adecuado para cubiertas y huellas y tabicas de escaleras.

La Armstrong Cork Co. ha elaborado además el $L$ 530: un extracto, basado en un adhesivo resistente al agua, para fijar losetas vinílicas a subsuelos directamente a la tierra impermeabilizada, o a subsuelos suspendidos donde se ha vertido agua anticipadamente.

\section{CAUCHO}

Los cementos de látex caucho son los tipos de adhesivos normalmente recomendados para los pavimentos de caucho, siendo este tipo de adhesivo facilitado por la Bostik Ltd.

La Evode Ltd. también suministra un cemento (el 5080): Se emplea para fijar losetas de caucho, laminados, amortiguadores de ruido, tabicas, etc. a pavimentos y escaleras de hormigón, terrazo, piedra o madera. Se aplica con brocha o con llana dentada sobre las dos superficies a unir y se hace suficientemente adherente para su utilización al cabo de 2030 minutos. Su resistencia final la alcanza al cabo de 24 horas. Otro método distinto para grandes superficies pavimentadas es aplicar el 5080 a la superficie del suelo y dejarlo secar. Después se aplica Evo-Stik-3503 (un cemento para suelos de caucho incoloro) a las losetas o a las láminas de caucho y, dentro de los 10 minutos siguientes, se colocan en su sitio las mismas. Acto seguido puede utilizarse el pavimento. 